\section{VISCOSITY AND LUBRICATION}

$A^{3}$

$\mathrm{T}$ a joint meeting of the Institute of Petroleum and the British Rheologists' Club, held at Manson House, Portland Place, London, W.1, on April 18, five papers dealing with different aspects of flow problems were discussed. Prof. E. N. da C. Andrade, president of the British Rheologists' Club, and Prof. F. H. Garner, president of the Institute of Petroleum, were the chairmen for the two sessions of the meeting.

Dr. G. Barr presented a paper on "The Precision and Accuracy of Viscometry Using B.S.I. Tubes". The paper dealt with data on viscometry collected by the Institute of Petroleum and analysed by Prof. Garner and Dr. A. H. Nissan. U-tube viscometers conforming to B.S.I. specifications were sent to a number of laboratories in Europe, the United States and Britain with three oils, with requests to determine flow-times of the oils in the tubes supplied. Further, each laboratory was invited to report the kinematic viscosity of the oils in absolute units at $20^{\circ} \mathrm{C}$., according to the method used in the laboratory and country concerned. As a result of analysis of the results returned by some of the laboratories - the outbreak of war prevented many from doing so-it was concluded that dimensional specifications of viscometric tubes were not sufficient to ensure agreement between tubes for the same oil in the same laboratory of better than $0 \cdot 1$ per cent. To ensure such a high degree of agreement a "dynamic quality control test' is suggested in which flow tests are made on a number of viscometers in order that master tubes may be selected from a set of apparently equally good tubes.

In comparing the viscosity of the oils as measured by British and American methods, it was found that there was a consistent deviation of 0.35 per cent between the two countries. In the discussion it was suggested that the variation in $g$ in different countries might influence the apparent value of the unit of kinematic viscosity in different countries and possibly account for the difference between the American and British determinations. It has since been pointed out by Dr. Nissan, however, that the viscometer tubes were calibrated by liquids of known viscosity, and therefore $g$ does not enter into the calculation of these results.

The dynamic control test was criticized in that U-tube viscometers which were found satisfactory by time of flow tests on two reference oils might not be satisfactory for times of flow different from those used for calibration; it would therefore be advisable to use more than two reference oils for calibration of viseometers in the dynamic flow test. The accuracy required in viscosity determinations is to some extent influenced by the determination of viscosity indexa measurement of viscosity variation with temperature-which was discussed in a later paper; the determination of viscosities with a maximum error of 0.1 per cent brings in many factors imperfectly controlled or understood at the present time. Among these factors, in so far as the reference oils are concerned, are thermal and mechanical hysteresis or the solution of air in oil. The influence of errors in timing including that of the operator was discussed. Dr. Barr pointed out that in changing from an aqueous solution to a hydrocarbon oil anomalies have been observed which are difficult to explain. If a No. 3 B.S.I. tube is used for the determination of a hydrocarbon oil and calibrated at intervals with the 60 per cent sugar solution, difficulties are experienced in obtaining consistent times of flows, even when the tubes have been very carefully cleaned between the oil and sugar-solution tests. It is difficult to imagine what effect can produce this result, as any retained film must be much too small to affect the dimensions of the tube.

The second paper dealt with "The Testing of Greases for Ball-Bearings" and was presented by Mr. S. R. Pethrick. It was emphasized that conventional methods for testing greases are of little assistance in the selection of greases for particular applications. It was suggested that tests on lime-base greases should include: (1) flow measurements at various rates of shear and at various temperatures, (2) an oxidation test with an examination of the oxidation products, and (3) a syneresis test involving capillary action. Soda- and lithia-base greases vary widely in texture, cohesion and adhesion, and some method of measuring these properties is desirable. The author described an apparatus using the torque exerted on the housing of a ball-bearing rotating under controlled conditions and lubricated by the grease, as a measure of the cohesion, adhesion and lubricating properties of the grease. The stability of the grease can also be determined in the same apparatus by churning it first and then measuring the torque under standard conditions.

The present standard methods of test for greases, such as penetration or drop point, while of value for routine checking of a particular product, do not render it possible to select a grease for a particular application without a full-scale test in the equipment to be lubricated.

The development of bearing tests for greases should enable such a selection to be made much more readily and might lead to a more precise definition of physical properties which can be characterized by fundamental measurements.

It was suggested that, in the main, greases are used at moderate temperatures at fairly high speeds and that such conditions should supplement those suggested by Mr. Pethrick.

The second half of the session was opened by a paper on "A Rational Basis for the Viscosity Index System. Part I", by Mr. E. W. Hardiman and Dr. A. H. Nissan. The viscosity index of an oil is given as a comparison of the drop in its viscosity between $100^{\circ}$ and $210^{\circ} \mathrm{F}$. with those of two oils, one of low variation in viscosity with temperature ( $H$ series) and another of high variation ( $L$ series) for the same temperature range. Thus

$$
\text { Viscosity Index }=\frac{L-U}{L-H} \times 100,
$$

where $U$ is viscosity of the oil at $100^{\circ} \mathrm{F}$., cs. ; $L$ and $H$ are viscosities at $100^{\circ} \mathrm{F}$. of the series $L$ and $H$ oils respectively, having the same viscosity at $210^{\circ}$ F. as the oil under test, cs.

Tables were issued by the originators of the V.r. (viscosity index) system from which $L$ and $H$ can be read. This system has been adopted as a standard method for petroleum oils both in the United States and Great Britain. It appears that, for viscosity index values exceeding 140 , the value of the index obtained from the tables and this equation are not unique solutions, since two oils both having the same viscosity at $100^{\circ} \mathrm{F}$. but very different values of viscosity at $210^{\circ} \mathrm{F}$. can give the same viscosity index. The authors presented a method whereby the index can be calculated as 
Viscosity Index $=(60 \cdot 0-\operatorname{antilog} n) \times 3 \cdot 63 ;$

$$
\text { where } \quad n=\frac{\log U-0.4336}{\log \text { viscosity at } 210^{\circ} \mathrm{F}} \text {. }
$$

This viscosity index is a single-valued function. Furthermore, this scale does not differ fundamentally from the Dean and Davis original V.I. system between 0 and 100 , but corrects its anomalies above 140 .

The viscosity index scale was criticized because it is not directly connected with the temperature slope and also because it is not additive as regards mixtures ; but it was pointed out that the law of mixtures for viscosity even of pure liquids is as yet not fully understood. From the viscosity index and viscosity at one temperature, it is possible by the use of charts, such as that issued by The American Society for Testing Materials, to ascertain viscosities over a range of temperature, and with the modified scale suggested in the paper this can be done with oils of very flat viscosity-temperatures such as are now being made by the employment of special additives to lubricating oils. The scale can be applied to oils with no change in viscosity with temperature which would have a viscosity index of around 200 and even to oils which show an increase in viscosity with rise in temperature. For the modified scale to be of value in characterizing some of the more recently developed lubricants for which the original viscosity index scale is not satisfactory, it must be adopted as a standard method by such bodies as the American Society for Testing Materials and the Institute of Petroleum Standardization Committee.

Dr. A. Lahiri presented a paper on "The Problem of Engine Deposits", by Dr. E. W. S. Mardles and himself. The paper is an extensive report on rheological and other colloidal studies of oils under oxidizing conditions simulating very closely those existing in internal combustion engines. The oxidizing apparatus can be used as a rotating viscometer of the Stormer type. Studies of specific viscosity have revealed the probable shapes of dispersions in aero-engine oils, while work with the rotating viscometer on oxidized oils has shown that rigidity develops slowly at first with time; then the oxidizing oil suddenly gelates when the concentration and polymerization of the oxidized products reach a critical value. The tendency of oils to keep in suspension soot or other detritus has also been studied. In general, a high degree of flocculation of carbon black, etc., results in high specific viscosity, high sedimentation-rates and volumes, high rigidities and yield values of the suspension.

In the discussion it was pointed out that performance tests on lubricating oils for use in internal combustion engines have been extensively developed using engines of different types, but it was felt that such tests are not complete unless information can be derived from the used oils in addition to that obtained from the condition of the engine after the test. The work described in the paper suggested a new and logical approach to this problem. In the selection of temperatures used for the oxidation tests described, the authors used thermocouples inserted at various points in pistons of aro-engines, and found that the temperature at which the oil functions is of the order of $200-300^{\circ} \mathrm{C}$.; and hence the fact must be faced that oxidation takes place at such tempera. tures. Within this range of temperatures there is, however, a marked difference in the behaviour of the same oil; thus for the same oil at $200^{\circ} \mathrm{C}$. gelation developed in 40 hours, whereas at $235^{\circ} \mathrm{C} .5$ hours was sufficient. For the chromatographic examination of used oils columns of $2 \mathrm{in}$. diameter and $6 \mathrm{ft}$. long have been used with various adsorption media such as activated silica.

The final paper was presented by Dr. A. S. C. Lawrence on "Lubricating Greases". Lubricating greases are mixtures of soaps dispersed in oil. If a soap is mixed with a hydrocarbon at low tempera. tures, it exists as a solid suspension. At a certain temperature $T_{1}$, the system assumes a gel structure which it maintains up to another critical temperature $T_{2}$, when it becomes a fluid solution of soap in the hydrocarbon. Peptizers may be used to change suspensoids of soap in oil into gels. A tentative structure of the gel by co-ordination was given. The rheology of greases was very briefly given.

Attention was directed to the paucity of information on the temperature-flow relations of greases, although such information would be of direct practical interest and also of great value in determining the energy of flow of the different phases in grease.

The importance of rate of cooling on the structure of greases was emphasized in the discussion, which largely centred about the application of knowledge grined in the investigation of soaps for pure fatty acid to commercial grease manufacture. The character of the mineral oil used is a factor of importance, and certain types of refined oils are unsuitable. Although the water content of greases is very low, and cannot be detected readily by electrical conductivity measurements, it plays an important part in peptization, that is, in increasing the degree of dispersion : it is possible that it acts as a hydrolyser of the soap and that the most effective peptizer is stearic or other fatty acid.

It was pointed out that although greases prepared from more than one metal may result in loss of consistency, in practice lime and soda greases and extreme pressure greases containing lead and calcium are found to be required industrially. Pure anhydrous sodium soaps of the fatty acids have probably never been prepared, although aluminium tri-stearate can be prepared and forms gels as do the other aluminium stearates.

All the papers and discussions reported here will be published in a separate volume by the Institute of Petroleum.

\section{DENTAL HEALTH IN BRITAIN}

$T$ HE Interim Report of the Interdepartmental Committee on Dentistry (Cmd. 6565. H.M. Stationery Office, 1944) records this Committee's opinion that the dental health of Britain is bad and that its effect upon general health is also bad. The dental profession itself cannot be blamed for this. Its ideals are high. They see in dentistry, not merely attention to teeth, but also that basic relation between dental disease and general ill-health which is the basis of the scheme of dental education outlined by C. Bowdler Henry (Lancet, 26, Jan. 6, 1945), who advocates a basic medical education for dental students and also the education of stomatologists who would act as consultants to dentists and would study dental problems in relation to other diseases and to the general biology of man. But the best dental profession in the world cannot operate in a vacuum; it must have the respect and co-operation of the people whom it seeks to serve; and the facts 